\title{
Stimulation of Thermogenesis via Beta-Adrenergic and Thyroid Hormone Receptors Agonists in Obesity Treatment - Possible Reasons for Therapy Resistance
}

\section{Alina Kurylowicz ${ }^{1,2^{*}}$}

${ }^{1}$ Department of Human Epigenetics, Mossakowski Medical Research Centre, Polish Academy of Sciences, Poland

${ }^{2}$ Department of Internal Medicine and Endocrinology, Medical University of Warsaw, 1a Banacha Street, 02-097 Warsaw, Poland

\begin{abstract}
The worldwide epidemic of obesity and the limited effectiveness of the available treatments led to a renewed interest in developing therapeutic approaches which would reduce obesity by increasing energy expenditure. Knowledge of the mechanism involved in the regulation of thermogenesis in mammals has led to the belief that compounds activating adrenergic receptors beta and/or thyroid hormone receptors may be effective in obesity treatment. However, the translation of the results obtained in the in vitro and in animal studies on humans occurred to be not as direct and effective as expected. This mini-review discusses the potential role of thermogenesis impairment in development of human obesity as well as possible limitations in the application of thermogenic compounds in obesity treatment.
\end{abstract}

\section{Key words}

Obesity treatment; Thermogenesis; Adrenergic receptors beta; Thyroid hormone receptors.

\section{Introduction}

The imbalance between energy intake and expenditure accompanied by the collapse of mechanisms protecting against the excessive accumulation of energy reserves are considered to be the main causes of obesity [1]. Accordingly, available treatments of obesity are aimed at decreasing calorie intake and/or increasing energy expenditure. However, long-term effects of various non-invasive methods including diets and pharmacotherapy with drugs reducing intestinal ingestion are unsatisfactory. Therefore, bariatric surgery, albeit expensive and potentially harmful, seems to be most effective [2]. Such situation has led to a renewed interest in developing therapeutic approaches which would reduce obesity by increasing energy expenditure. In this minireview the potential role of thermogenesis impairment in development of human obesity as well as possible limitations in the application of thermogenic compounds, namely agonists of the adrenergic receptors beta and thyroid hormone receptors, in obesity treatment are discussed.

\section{Brown Adipose Tissue in Human Energy Expenditure}

In small mammals and in human newborns, non-shivering (adaptive) thermogenesis in brown adipose tissue (BAT) is the most important regulatory mechanism for maintaining body temperature. Energy produced in the BAT mitochondria, due to the oxidation of lipolysis-derived fatty acids, is not used to produce high-energy bonds of adenosine-5'-triphosphate (ATP), but is released as heat, mostly thanks to uncoupling protein 1 (UCP1) [3].

It was believed that in humans, age progression is accompanied by a complete atrophy of BAT; however, novel methods of imaging led to the identification of BAT stores in several areas of the adult human body, as well as of cells reminding brown adipocytes dispersed within the visceral white adipose tissue (WAT) also known as beige/brite adipocytes [4].

The prevalence and activity of BAT differ between individuals and are inversely related to age, body mass index (BMI) and the total fat content [5]. BAT activity may vary even in the same subject, depending on cold exposure which is the most powerful and physiological stimulus for its activation. Activity of the cold-stimulated human BAT measured by the uptake of fatty acids and glucose (per gram of tissue) can be higher than in insulin-stimulated skeletal muscle [6]. Apart from its contribution to cold-induced thermogenesis, recent human studies demonstrated that BAT also participates in diet-induced thermogenesis, which may constitute up to $10 \%$ of whole body energy expenditure [7]. Therefore, stimulation of thermogenesis in brown adipocytes seems to be an attractive therapeutic pathway in treatment of obesity and related metabolic disorders.

\section{Regulation of Adaptive Thermogenesis}

The function of brown adipocytes is under strict neurohormonal control. In organisms exposed to cold, stimuli from the Para ventricular nucleus and from the preoptic area of hypothalamus lead to the increased noradrenaline release from the sympathetic nerve fibers in the vicinity of BAT. Such $\beta$-adrenergic signaling, executed by the activation of the $\beta 1$ adrenergic receptor (ADRB1), predominantly results in the proliferation of brown adipocytes, while signaling executed by the $\beta 2$ and $\beta 3$ adrenergic receptors (ADRB2 and ADRB3, respectively), results mainly in the activation of lipolysis (in WAT and in BAT) and of thermogenesis (in BAT) [8]. Chronic symphatetic stimulation, observed in patients with catecholamines secreting tumors, leads to the induction of UCP-1 positive brown-like (beige) adipocytes in WAT, and subsequently - to increased energy expenditure due to intense thermogenesis as well as to body fat reduction caused by the

*Corresponding author: Alina Kurylowicz, Department of Human Epigenetics, Mossakowski Medical Research Centre, Polish Academy of Sciences, 5 Pawinskiego Street, 02-106 Warsaw, Poland, Tel: +48 22 6086591; E-mail: akurylowicz@imdik.pan.pl

Received March 03, 2015; Accepted March 24, 2015; Published March 30, 2015

Citation: Kurylowicz A (2015) Stimulation of Thermogenesis via Beta-Adrenergic and Thyroid Hormone Receptors Agonists in Obesity Treatment - Possible Reasons for Therapy Resistance. J Pharmacogenomics Pharmacoproteomics 6: 145. doi:10.4172/2153-0645.1000145

Copyright: () 2015 Kurylowicz A. This is an open-access article distributed unde the terms of the Creative Commons Attribution License, which permits unrestricted use, distribution, and reproduction in any medium, provided the original author and source are credited. 
Citation: Kurylowicz A (2015) Stimulation of Thermogenesis via Beta-Adrenergic and Thyroid Hormone Receptors Agonists in Obesity Treatment Possible Reasons for Therapy Resistance. J Pharmacogenomics Pharmacoproteomics 6: 145. doi:10.4172/2153-0645.1000145

Page 2 of 7

increased lipolysis and glycogenolysis [9].

The adrenergic system interacts with thyroid hormones (TH) in controlling the non-shivering thermogenesis to counteract environmental stress. While adrenergic stimulation provides the means for rapid responses, triiodothyronine (T3) increases the capacity of cells to respond to catecholamines and maintains a metabolic rate appropriate for the availability and mobilisation of fatty acids from fat stores to ensure adrenergic responses [10]. Apart from the influence on ADRB density, T3 may also potentiate adrenergic stimulation via other mechanisms including enhancing the intracellular accumulation of cyclic adenosine monophosphate (cAMP) [11]. In turn, cold-induced noradrenergic stimulation of brown adipocytes results in the local activation of the type 25 -iodothyronine deiodinase, which catalyzes the conversion of the prohormone - thyroxin (T4) to T3. Subsequently, T3 acting by its nuclear receptors (TRs) bound to the thyroid hormoneresponse elements present in the regulatory regions of various genes, including the genes for uncoupling proteins, increases their expression. Catecholamines may also potentiate the activity of $\mathrm{T} 3$ by increasing the retention of TRs in the nucleus or by increasing the recognition of DNA sequences through protein kinase A-mediated phosphorylation of TRs [12].

Knowledge of the mechanisms involved in regulation of thermogenesis in adipose tissue suggests two potential strategies for its pharmacological activation in treatment of obesity. The first strategy is based on adrenergic receptors beta (ADRBs) activation, while the second - on stimulation of thyroid hormone receptors (TRs).

\section{Adrenergic Receptors Beta as Targets for Obesity Treatment}

ADRBs are members of the $G$ protein-coupled receptor family that after activation induce the adenyl cyclase leading to the increase in intracellular cAMP levels. cAMP acts as a second messenger activating protein kinase $A$ that subsequently results in the phosphorylation of multiple targets [13]. In adipose tissue, this process may result in adipocytes proliferation and induction of nonshivering thermogenesis (BAT) as well as in the mobilization of stored fatty acids for lipolysis (WAT). There is mounting evidence coming from animal models and from genetic studies that the dysfunction of ADRBs may play a role in the development of obesity.

\section{Animal studies}

Adipocytes from genetically obese (ob/ob) mice display an impaired response to beta-adrenergic stimulation due to significantly reduced expression of all ADRBs isoforms in BAT and WAT [14]. Crucial role of ADRBs in mediating thermogenesis and lipolysis was confirmed by experiments performed on mice with the combined targeted disruption of the three ADRBs (TKO mice) which have increased susceptibility to cold-induced hypothermia as well as to diet-induced obesity $[15,16]$. Animals with selective knockout of the adrb1 easily develop hypothermia due to the severely disturbed cold-induced and diet-induced thermogenesis and when placed on a high-fat diet - gain significantly more weight than wild type controls and develop features of the metabolic syndrome that include: impaired glucose tolerance, hypercholesterolemia, and hypertriglyceridemia [17]. Although targeted disruption of the adrb2 gene does not impair cold- and dietinduced thermogenesis in mice and seems to have no influence body weight, adiposity and lipids metabolism, it impairs glucose homeostasis possibly by accelerating hepatic glucose production and insulin secretion [18]. Similarly, mice with adrb3 knockout, due to the normal function of the ADRB1, are able to maintain core body temperature in cold but their resting metabolic rate is lower compared to wild-type controls that predispose them to obesity [19].

\section{Genetic studies}

There is also indirect evidence from genetic studies that ADRBs receptors might participate in the regulation of body weight in humans, because certain polymorphisms in their genes were associated with metabolic complications and increased weight gain (Table 1).

The ADRB2 gene (encoding ADRB2) is located on chromosome 5q31-32 and composed of one exon, spanning $2 \mathrm{~kb}$ of DNA. This gene contains several single nucleotide polymorphisms (SNPs) both in the encoding sequence as well as within the 5'-untranslated region (UTR) that were found to be associated with obesity. In vitro studies showed that despite having no influence on ligand binding or adenyl cyclase activity, the A285G (rs1042713, causing Arg16Gly substitution) and C318G (rs1042714, causing Gln27Glu substitution) SNPs, located in the extracellular $\mathrm{N}$-terminus of $A D R B 2$, determinate the efficacy of the agonist-promoted receptor down-regulation. While the $285 \mathrm{G}$ variant enhances, the $318 \mathrm{G}$ is not only associated with a strong resistance to the down-regulation, but also encodes the protein that is less susceptible to degradation [20]. Creation of double mutants let to assess the combined effect of these two SNPs and showed that in the $285 \mathrm{G} / 318 \mathrm{G}$ combination, the presence of the $285 \mathrm{G}$ variant determinates the biological effect and the protein is more susceptible to agonist-promoted down regulation, while the $285 \mathrm{~A} / 318 \mathrm{G}$ mutant is completely resistant to this process. The strong linkage disequilibrium between these two polymorphisms and their interaction may partially explain the discrepancies between the genetic studies regarding their association with obesity. The $318 \mathrm{C}$ allele was associated with higher risk of weight gain in inactive French and Swedish men as well as in Spanish women [21-23]. However, subsequent studies did not manage to replicate this association [24] or even pointed to the opposite variant as the causative one in Caucasians [25].

In turn, the 285G allele (alone as well as in combination with $318 \mathrm{G}$ ) was found to be associated with weight gain and blood pressure elevation in Japanese [24-26] although previous study carried in the same population denied this association [27].

The $\mathrm{T}$ allele of the ADRB2 C730T SNP (rs1800888, causing Thr164lle substitution) located in the fourth membrane-spanning domain impairs both receptor affinity towards agonists as well as its interaction with $G$ protein resulting in lower adenyl cyclase activity [28]. In some populations this variant was not only directly associated with obesity [29], but also considered as a predisposing one, since it might determine exercise capacity [30].

Another functional SNP in ADRB2 vicinity is a T-47C change (rs1042711, causing Arg19Cys substitution) located in 5'-leader cistron (a peptide encoded by a short open reading frame 102 bp upstream the $A D R B 2$ coding block). The $-47 \mathrm{C}$ variant results in lower $A D R B 2$ expression on protein level and its impaired ability to activate adenyl cyclase [31]. A combination of -47C/285A/318C (Cys19/Arg16/Gln27) was found to be a risk-haplotype for hypertension and obesity [32]. However, the interpretation of most case-control studies regarding the association between ADRB2 SNPs with obesity is difficult due to several reasons, including ethnic and gender-associated differences as well as the lack of haplotypes analysis and inadequate understanding of how the combination of different variants affect the receptor function, not to mention the gene-gene interactions. It is also worth mentioning that recent meta-analysis did not confirm the association of the ADRB2 variants with obesity [33]. 
Citation: Kurylowicz A (2015) Stimulation of Thermogenesis via Beta-Adrenergic and Thyroid Hormone Receptors Agonists in Obesity Treatment Possible Reasons for Therapy Resistance. J Pharmacogenomics Pharmacoproteomics 6: 145. doi:10.4172/2153-0645.1000145

Page 3 of 7

\begin{tabular}{|c|c|c|c|c|c|c|}
\hline Gene & Polymorphism (rs) & Base substitution & $\begin{array}{l}\text { Amino acids } \\
\text { substitution }\end{array}$ & Variant & Functional consequences & Reference \\
\hline$A D R B 1$ & rs1801252 & A231G & Ser49Gly & $231 \mathrm{G}$ & $\uparrow$ receptor down regulation & [38] \\
\hline \multirow[t]{2}{*}{$(10 q 24-26)$} & rs1801253 & G1251C & Gly389Arg & $1251 C$ & $\uparrow$ interaction with $\mathrm{G}$ protein & [39] \\
\hline & & & & & $\uparrow$ response to antagonists & [40] \\
\hline$A D R B 2$ & rs1042711 & $\mathrm{T}-47 \mathrm{C}$ & Arg19Cys & $-47 C$ & $\downarrow A D R B 2$ expression & [31] \\
\hline \multirow[t]{6}{*}{$(5 q 31-32)$} & & & & & $\downarrow$ interaction with G protein & [31] \\
\hline & rs1042713 & A285G & Arg16Gly & $285 G$ & $\uparrow$ receptor down regulation & {$[20]$} \\
\hline & rs1042714 & C318G & Gln27Glu & $318 G$ & $\downarrow$ receptor down regulation & {$[20]$} \\
\hline & & & & & $\downarrow$ receptor degradation & [20] \\
\hline & rs1800888 & C730T & Thr164lle & $730 \mathrm{~T}$ & $\downarrow$ affinity towards ligands & [28] \\
\hline & & & & & $\downarrow$ interaction with G protein & [28] \\
\hline$A D R B 3(8 \mathrm{p} 12)$ & rs4994 & T190C & Trp64Arg & $190 \mathrm{C}$ & $\begin{array}{r}\downarrow \text { response to agonists } \\
\text { lipolysis }\end{array}$ & {$[34,36]$} \\
\hline
\end{tabular}

Table 1: Obesity-associated functional polymorphisms in genes encoding adrenergic receptors beta(ADRB).

Among the various polymorphisms identified in the ADRB3 gene (encoding ADRB3, located on chromosome 8p12 and composed of two exons spanning $1.4 \mathrm{~kb}$ and $0.7 \mathrm{~kb}$ of DNA, respectively), the rs4994 T190C SNP causing amino acids substitution (Trp64Arg) in the first intracellular loop of the receptor was the most frequently studied in the context of its relationship with obesity. In initial in vitro studies, the presence of the 190C allele was associated with lower receptor response to agonists as well as with impaired catecholamine-stimulated lipolysis. However, other researchers did not observe any differences in the receptor function between carriers of particular alleles [34]. In some case-control studies, carriers of the 190C allele showed tendency to lower metabolic rate, abdominal obesity and insulin resistance compared to the individuals homozygous for the $190 \mathrm{~T}$ variant. Yet, the results of further studies were not so univocal, probably due to the heterogeneity of the studied populations. A large meta-analysis involving results of 97 case control-studies and over 44000 individuals suggested association of the 190C allele with BMI in East Asians but not in Caucasians [35].

The T190C polymorphism (rs4994) remains in strong linkage disequilibrium with two synonymous SNPs: G1856T (rs4997) and G3139C (rs4998) constructing the two major haplotypes: 190T-1856G3139G - named a "Trp haplotype" and 190C-1856T-3139C - named an "Arg haplotype". The in vitro studies analyzing influence of these haplotypes on ADRB3 function showed that adipocytes possessing the "Arg haplotype" present lower lipolytic activity in response to catecholamines [36].

Among SNPs identified in the ADRB1 gene (encoding ADRB1, located on chromosome 10q24-26 and composed of one exon $2.4 \mathrm{~kb}$ long) two of them, A231G (rs1801252 causing Ser49Gly substitution) and G1251C (rs1801253, causing Gly389Arg substitution), have been most commonly studied due to their high (more than 10\%) frequency in different populations [37].

The A231G SNP is localized in the extracellular N-terminus of the receptor, near the first transmembrane-spanning domain. Although functional studies found no differences between the 231A and $231 \mathrm{G}$ alleles in ligands binding affinity, and in the basal and stimulated adenyl cyclase activity, the $231 \mathrm{G}$ variant was associated with the enhanced long-term agonist-promoted down-regulation of the receptor [38]. In a case-control association study, the $231 \mathrm{G}$ variant was found to be associated with higher BMI in type 2 diabetic patients [24]. It was proposed that the reduced signaling via ADRB1 in 231G positive individuals may be associated with attenuated lipolysis and therefore with the increase in BMI. However other studies did not confirm this association [37].
The G1251C SNP is located in the vicinity of the seventh transmembrane-spanning domain and may influence receptor coupling to Gs. In functional studies, the 1251C allele was associated with higher basal and isoproterenol-stimulated adenyl cyclase activity but also with greater response to beta adrenergic antagonist (metoprolol) [38-40]. However, in experiments performed in human adipocytes there was no difference between the two variants in the cells lipolytic sensitivity and maximum lipolityc capacity [41]. In some cohort studies, the 1251C allele was associated with higher BMI due to the enhanced adiposity [42], while other researchers did not confirm this association [43]. Interestingly, in a longitudinal study assessing risk of obesity over 24year observation period, a significant interaction between the ADRB1 $1251 \mathrm{G}$ (Gly389) and ADRB2 285G (Gly16) alleles in creating a risk of the weight gain in men was observed. This association could be explained by a cumulative effect of the lower activity of ADRB1 and lower ADRB2 density. In woman, the ADRB1 $1251 G$ homozygosity was associated with obesity when interacted with ADRB3 190C variant, probably due to the combined effect of reduced functionality of the ADRB1 $1251 G$ allele and reduced sensitivity of the ADRB3 190C variant [44].

In summary, given the (i) ethnic heterogeneity, (ii) inadequate number of study participants (iii) linkage disequilibria between the studied variants and (iv) complex interactions among the genes encoding ADRBs, it is often difficult to draw firm conclusions from most case-control studies regarding associations of polymorphisms within these genes and obesity. The reliable meta-analysis was performed only for the ADRB3 T190C (Trp64Arg) SNP and on the basis of its results, one can conclude that the 190C (Arg64) is an obesity-predisposing allele in Asian populations. However, pathophysiological mechanisms linking this polymorphism with increased adiposity are less clear since results of the functional studies regarding its influence on receptor activity are unequivocal.

\section{ADRBs ligands in treatment of obesity}

Given their crucial role in mediating cold-induced thermogenesis, ADRBs seemed to be promising targets for obesity treatment. However, in this case imitating of physiology was more difficult than expected. While mild cold exposure in humans leads to the activation of a sympathetic response only in certain organs (BAT and peripheral vessels), systemic administration of nonselective $\beta$-adrenergic receptors agonists (ephedrine or isoprenaline) leads to the general adrenergic response and increases energy consumption by a number of organs, including the heart, liver and skeletal muscle, but exerts little effect on thermogenesis in brown adipocytes $[6,45]$. Doses of ephedrine that are effective in stimulation of BAT in rodents are unacceptable 
Citation: Kurylowicz A (2015) Stimulation of Thermogenesis via Beta-Adrenergic and Thyroid Hormone Receptors Agonists in Obesity Treatment Possible Reasons for Therapy Resistance. J Pharmacogenomics Pharmacoproteomics 6: 145. doi:10.4172/2153-0645.1000145

Page 4 of 7

in humans because of their cardiovascular effects. Similarly, despite its unquestionable role in mediating cold-induces thermogensis clinical application of norepinephrine is limited due to its adverse effects on the cardiovascular system. Interestingly, while stimulation of ADRB1 and ADRB2 by isoprenaline does not activate BAT in humans, their blockade by the administration of propranolol decreases glucose uptake in BAT in patients in thermoneutral conditions [46]. The possible explanation of this phenomenon is that high concentrations of sympatomimetics in the postsynaptic areas required for the effective stimulation of brown adipocytes cannot be achieved by their systemic administration.

Therefore, novel selective agonists of ADRBs have been developed in attempt to stimulate brown adipocytes proliferation and activation. The in vitro studies performed on human multipotent adipocyte-derived stem cells suggest that activation of ADRB3 receptors by a selective agonist (CL-316243) leads to the increased UCP1 mRNA synthesis and differentiation towards brown adipocytes [19]. In rodents, ADRB3 ligands induce intense thermogenic and lipolytic response that results in the loss of fat mass without affecting the lean body mass and in the subsequent improvement of glucose control [47]. Moreover, acting in hypothalamus, CL-316243 occurred to be effective in reducing food intake in mice via leptin-independent mechanism and despite increased hypothalamic expression of the orexigenic neuropeptides [48]. Despite promising data from the in vitro and from animal studies, these agents occurred to have limited efficacy in humans, probably due to the (i) lower number of ADRB3 in human adipose tissue than in transfected cell-lines used for the in vitro experiments, (ii) poor selectivity of the compounds for the human ADRB3, and (iii) different contribution of white and brown adipocytes in rodents and in humans [49]. The lower expression of $A D R B 3$ in adipose tissues of obese subjects may constitute another reason of low efficacy of these compounds in obesity treatment [50].

Therefore, one can conclude that identifying highly selective agonists that are able to selectively stimulate the low numbers of ADRB3 in human tissues is challenge and is additionally compounded by pharmacodynamic differences between rodents and humans.

\section{Thyroid Hormone Receptors as Targets for Obesity Treatment}

Thyroid hormone receptors (TRs) belong to the nuclear hormone receptor superfamily and act as ligand-dependent transcription factors regulating expression of target genes. Two genes THRA (located on chromosome 17q12-22, containing 11 exons) and THRB (on chromosome 3p22-24, containing 17 exons) encode TR $\alpha$ and TR $\beta$ respectively. Both of them exist in several isoforms due to the alternative splicing or use of alternative promoters. The isoforms have tissue- and organ specific localisation, with TRal being a predominant isoform in the brain, bone, heart and intestine, TR 22 - a variant receptor that lacks a functional hormone-binding site and antagonizes TRal action, TR $\beta 1$ dominating in liver, kidney and thyroid and TR $\beta 2$ being a chief form involved in the regulation of the hypothalamus-pituitary axis and in the neurosensory development [51]. Both TRal and TR $\beta 1$ are also expressed in human adipose tissue $[50,52]$ and there is data coming from the observational, animal and genetic studies suggesting that they could constitute potential targets for obesity treatment.

\section{Observational studies}

Weight gain and increased adiposity are typical features of hypothyroidism and cross-sectional analyses adjusted for age, BMI and total body fat confirmed independent and inverse association of free thyroxin (fT4) level with volume of the visceral fat stores [53]. There are also studies suggesting that thyroid status may influence not only general adiposity but also distribution of adipose tissue pointing at inverse correlation between the fT4 levels and visceral adiposity and at the positive correlation of TSH with the amount of subcutaneous fat [54]. This phenomenon can be partially explained by the differences in the TRs expression between the visceral and subcutaneous tissues as well as between obese and slim individuals [50]. The decreased expression of TRs in adipose tissues of obese individuals is also suggested as a potential mechanism of a relative resistance to thyroid hormone that manifests itself by the increased fT3 serum levels [52] and correlates positively with the increase in weight [55]. Another explanation for the elevation of fT3 (and thyroid stimulating hormone - TSH) in obese individuals is the regulatory action of leptin - an adipokine secreted by the adipose tissue that can promote expression of the thyreotropin releasing hormone (TRH) gene in the hypothalamus and increase peripheral conversion of $\mathrm{T} 4$ to $\mathrm{T} 3$ via stimulation of deiodinases. Finally, it is also postulated that thyroid function abnormalities observed in obese individuals may constitute an adaptive process aimed at the increase of the resting energy expenditure [56].

\section{Animal studies}

The metabolic phenotype of mice with targeted disruptions of thra is very variable, depending on the mutation. The thra -/- mice are cold intolerant and have higher energy expenditure in room temperature. Despite the increased appetite, they are leaner than the wild type animals. Interestingly these differences disappear in thermoneutral conditions, suggesting that exposition to cold results in thra-/- mice in activation of facultative thermogenesis pathway (increased sympathetic activation) that is more energy demanding and associated with relative resistance to diet-induced obesity [57]. Animals with frame shift thra mutations (TRa1-P398H and TRa1-L400R), resulting in reduced T3 affinity and/or decreased binding to the cofactors, have reduced coldinduced thermogenesis. In contrast, TR 1 1-R384C mice (with decreased receptor affinity towards T3) are hyperfagic and resistant to obesity due to a centrally induced hypermetabolism caused by apo-TRh1 (binding DNA without binding T3). In turn TRa1-P453H mice (with impaired receptor binding capacity) demonstrate increased body fat and insulin resistance [58].

In analogous experiments with thrb-/- mice, no major disturbances in body weight regulation and cold-induced thermogenesis have been observed, while in mice with targeted thrb mutations severe growth retardation is accompanied by an impaired weight gain. It is suggested that high T3 levels lead in these animals to the increased activation of TRa1 [59].

\section{Genetic studies}

Heterozygous mutations within genes encoding TRs, causing reduced receptor affinity towards $\mathrm{T} 3$ or impaired interaction with transcription cofactors, lead to the development of resistance to thyroid hormone (RTH) syndromes [58]. The clinical picture of RTH may vary depending on the affected TR isoform and on the type of the mutation which can be inherited or occur de novo only in some organs and tissues [60]. Although over 170 different mutations in THRB have been described to date, in general the RTH $\beta$, caused by heterozygous mutations in the ligand-binding domain of THRB, is characterized by high serum TH levels with nonsuppresed TSH leading to goiter, tachycardia, hyperfagia and raised energy expenditure [58]. It is speculated that hyperfagia and increased resting energy expenditure 
Citation: Kurylowicz A (2015) Stimulation of Thermogenesis via Beta-Adrenergic and Thyroid Hormone Receptors Agonists in Obesity Treatment Possible Reasons for Therapy Resistance. J Pharmacogenomics Pharmacoproteomics 6: 145. doi:10.4172/2153-0645.1000145

Page 5 of 7

observed in patients with classical RTH $\beta$ is mediated by elevated TH acting centrally on TRa [61].

Patients with mutations in the THRA region unique for TRa1, causing a very rare RTHa has normal body temperature, but lower basal metabolic rate and tendency to gain weight with age [62].

A recent study suggest that two SNPs (rs12939700 C1890A and rs $1568400 \mathrm{~A}-635 \mathrm{G}$ ) located in the critical regions of THRA involved in the regulation of splicing may contribute to the development of obesity [63]. In high cardiovascular risk cohort carriers of the rs $12939700 \mathrm{~A}$ allele had higher weight and higher prevalence of obesity than CC homozygotes. In turn, in general population and in the longitudinal study, individuals homozygous for the G variant of the A-635G SNP had significantly higher baseline BMI as well as higher increase in weight and in waist circumference after the 6-year follow-up. What is interesting, the analysis of this SNP in high cardiovascular risk patients showed a gene-diet interaction: only the individuals with GG genotype and a high intake of saturated fats showed a significant association with increased BMI. None out of several other SNPs identified in THRA and THRB was associated with obesity [64].

\section{TRs ligands in treatment of obesity}

In animal model of obesity (ob/ob mouse), the administration of exogenous T3 decreases body weight and body fat without a significant change in body protein content [65]. There is a lack of welldesigned prospective studies regarding the use of thyroid hormones in euthyroid obese patients. Available studies were conducted on relatively small number of patients and the effect of hormone therapy on the weight loss was not consistent [66]. Use of thyroid hormones in supraphysiological doses is associated with serious cardiological complications and osteoporosis and these effects are traditionally associated with the activation of TR $\alpha$ receptors. Therefore, a number of selective TR $\beta$ agonists are being tested for their efficacy in obesity treatment. The use of selective TR $\beta$ ligands has been linked to metabolic improvement in animal models of diet-induced obesity, nonalcoholic liver disease, and genetic hypercholesterolemia. GC-1, an agonist with 10 -fold higher affinity towards TR $\beta$ compared to TRa, was found to accelerate metabolic rate and reduce fat mass in rats without causing heart hypertrophy and bone mass loss [67]. The treatment of rats with another TR $\beta$ selective agonist GC-24 partially prevented the metabolic alterations (e.g. hyperisnulinemia and hypertriglicerydemia) associated with a hypercaloric diet by increasing energy expenditure in BAT [68]. However, this effect was more pronounced in initially normal-weight than in obese animals [69]. Another TR $\beta$ selective agonist KB-141 increased metabolic rate and lowered plasma cholesterol levels without tachycardia in lean rats. Moreover, its administration to obese Zucker $\mathrm{fa} / \mathrm{fa}$ rats improved glucose tolerance and insulin sensitivity suggesting that selective $\operatorname{TR} \beta$ activation may be a useful strategy to attenuate features of the metabolic syndrome [70].

Clinical trials with the use of selective TR $\beta$ ligands proved their efficiency in improving the lipid profile, while no significant effect on weight loss was noted, suggesting that the regulation of basal metabolic rate in humans is also dependent on TRa signaling [71]. This theory is supported by the experiments performed on hypothyroid mice, in which the treatment with the selective TR $\beta$ agonist (GC-1) alone failed to restore proper thermogenic function. It is suggested that TRa mediates in synergism between $\mathrm{T} 3$ and the adrenergic pathway, while induction of UCP1 expression depends on TR $\beta$ activation [72]. TRa (as it was mentioned above) seems to be also important in T3-dependent central regulation of satiety [73]. New TRa selective agonists are being studied in order to improve our understanding of the role of this isoform in termogenesis and other $\mathrm{T} 3$ regulated processes [74]. The effectiveness of these compounds, however, may be limited due to the decreased expression of THRA and THRB genes in adipose tissues of obese individuals $[50,52]$.

\section{Final Remarks and Conclusions}

The worldwide epidemic of obesity creates a need of developing new non-invasive methods of its treatment. Given the promising results of the in vitro and animal studies, the activation of thermogenesis in adipose tissue via adrenergic beta receptors and/or thyroid hormone receptor ligands seems to be an attractive therapeutic approach. However, the results of studies regarding the use of these compounds in the treatment of obesity in humans are largely disappointing. Among the probable causes of these discrepancies one should list: (i) differences in the mechanisms regulating thermogenesis and in its role in the body's energy expenditure in humans and rodents, (ii) genetic variations (polymorphisms and mutations) that may impair the function of the target receptors (ADRBs and TRs), and (iii) a decreased expression of ADRBs and TRs in adipose tissues of obese individuals that can significantly reduce the effectiveness of the therapy.

\section{Acknowledgements}

This work was supported by the Polish Ministry of Science and Higher Education grants NN402 557440

\section{References}

1. Guyenet SJ, Schwartz MW (2012) Clinical review: Regulation of food intake energy balance, and body fat mass: implications for the pathogenesis and treatment of obesity. J Clin Endocrinol Metab 97: 745-755.

2. Aronne LJ, Wadden T, Isoldi KK, Woodworth KA (2009) When prevention fails: obesity treatment strategies. Am J Med 122: S24-32.

3. Dawkins MJ, Scopes JW (1965) Non-shivering thermogenesis and brown adipose tissue in the human new-born infant. Nature 206: 201-202.

4. Saito $M(2013)$ Brown adipose tissue as a regulator of energy expenditure and body fat in humans. Diabetes Metab J 37: 22-29.

5. Ma SW, Foster DO (1986) Uptake of glucose and release of fatty acids and glycerol by rat brown adipose tissue in vivo. Can J Physiol Pharmacol 64: 609614.

6. Cypess AM, Chen YC, Sze C, Wang K, English J, et al. (2012) Cold but not sympathomimetics activates human brown adipose tissue in vivo. Proc Natl Acad Sci U S A 109: 10001-10005.

7. Vosselman MJ, Brans B, van der Lans AA, Wierts R, van Baak MA, et al. (2013) Brown adipose tissue activity after a high-calorie meal in humans. Am J Clin Nutr 98: 57-64.

8. Collins S, Surwit RS (2001) The beta-adrenergic receptors and the control of adipose tissue metabolism and thermogenesis. Recent Prog Horm Res 56 309-328.

9. Inokuma K, Okamatsu-Ogura $\mathrm{Y}$, Omachi A, Matsushita $\mathrm{Y}$, Kimura K, et al. (2006) Indispensable role of mitochondrial UCP1 for antiobesity effect of beta3adrenergic stimulation. Am J Physiol Endocrinol Metab 290: E1014-1021.

10. Silva JE (2006) Thermogenic mechanisms and their hormonal regulation Physiol Rev 86: 435-464

11. Michel-Reher MB, Gross G, Jasper JR, Bernstein D, Olbricht T, et al. (1993) Tissue- and subunit-specific regulation of G-protein expression by hypo- and hyperthyroidism. Biochem Pharmacol 45: 1417-1423.

12. Silva JE, Bianco SD (2008) Thyroid-adrenergic interactions: physiological and clinical implications. Thyroid 18: 157-165.

13. Wallukat G (2002) The beta-adrenergic receptors. Herz 27: 683-690.

14. Collins S, Daniel KW, Rohlfs EM, Ramkumar V, Taylor IL, et al. (1994) Impaired expression and functional activity of the beta 3 - and beta 1-adrenergic receptors in adipose tissue of congenitally obese (C57BL/6J ob/ob) mice. Mol Endocrinol 8: 518-527. 
Citation: Kurylowicz A (2015) Stimulation of Thermogenesis via Beta-Adrenergic and Thyroid Hormone Receptors Agonists in Obesity Treatment Possible Reasons for Therapy Resistance. J Pharmacogenomics Pharmacoproteomics 6: 145. doi:10.4172/2153-0645.1000145

Page 6 of 7

15. Bachman ES, Dhillon $H$, Zhang CY, Cinti S, Bianco AC, et al. (2002) betaAR signaling required for diet-induced thermogenesis and obesity resistance. Science 297: 843-845

16. Jimenez M, Léger B, Canola K, Lehr L, Arboit $P$, et al. (2002) Beta(1)/beta(2)/ beta(3)-adrenoceptor knockout mice are obese and cold-sensitive but have normal lipolytic responses to fasting. FEBS Lett 530: 37-40.

17. Ueta CB, Fernandes GW, Capelo LP, Fonseca TL, Maculan FD, et al. (2012) $\beta(1)$ Adrenergic receptor is key to cold- and diet-induced thermogenesis in mice. J Endocrinol 214: 359-365.

18. Fernandes GW, Ueta $\mathrm{CB}$, Fonseca TL, Gouveia $\mathrm{CH}$, Lancellotti $\mathrm{CL}$, et al (2014) Inactivation of the adrenergic receptor $\beta 2$ disrupts glucose homeostasis in mice. J Endocrinol 221: 381-390.

19. Mattsson CL, Csikasz RI, Chernogubova E, Yamamoto DL, Hogberg HT, et al. (2011) ß1-Adrenergic receptors increase UCP1 in human MADS brown adipocytes and rescue cold-acclimated B3-adrenergic receptor-knockout mice via nonshivering thermogenesis. Am J Physiol Endocrinol Metab 301: E11081118.

20. Green SA, Turki J, Innis M, Liggett SB (1994) Amino-terminal polymorphisms of the human beta 2-adrenergic receptor impart distinct agonist-promoted regulatory properties. Biochemistry 33: 9414-9419.

21. Meirhaeghe A, Helbecque N, Cottel D, Amouyel P (1999) Beta2-adrenoceptor gene polymorphism, body weight, and physical activity. Lancet 353: 896.

22. Hellström L, Large V, Reynisdottir S, Wahrenberg H, Arner P (1999) The different effects of a GIn27Glu beta 2-adrenoceptor gene polymorphism on obesity in males and in females. J Intern Med 245: 253-259.

23. Corbalán MS, Marti A, Forga L, Martínez-González MA, Martínez JA (2002) The $27 \mathrm{Glu}$ polymorphism of the beta2-adrenergic receptor gene interacts with physical activity influencing obesity risk among female subjects. Clin Genet 61: 305-307.

24. Nonen S, Yamamoto I, Liu J, Maeda M, Motomura T, et al. (2008) Adrenergic beta1 receptor polymorphism (Ser49Gly) is associated with obesity in type II diabetic patients. Biol Pharm Bull 31: 295-298.

25. Ehrenborg E, Skogsberg J, Ruotolo G, Large V, Eriksson P, et al. (2000) The Q/E27 polymorphism in the beta2-adrenoceptor gene is associated with increased body weight and dyslipoproteinaemia involving triglyceride-rich lipoproteins. J Intern Med 247: 651-656.

26. Masuo K, Katsuya T, Fu Y, Rakugi H, Ogihara T, et al. (2005) Beta2- and beta3-adrenergic receptor polymorphisms are related to the onset of weight gain and blood pressure elevation over 5 years. Circulation 111: 3429-3434.

27. Hayakawa T, Nagai Y, Kahara T, Yamashita H, Takamura T, et al. (2000) GIn27Glu and Arg16Gly polymorphisms of the beta2-adrenergic receptor gene are not associated with obesity in Japanese men. Metabolism 49: 1215-1218.

28. Green SA, Cole G, Jacinto M, Innis M, Liggett SB (1993) A polymorphism of the human beta 2-adrenergic receptor within the fourth transmembrane domain alters ligand binding and functional properties of the receptor. J Biol Chem 268 23116-23121.

29. Pereira AC, Floriano MS, Mota GF, Cunha RS, Herkenhoff FL, et al. (2003) Beta2 adrenoceptor functional gene variants, obesity, and blood pressure level interactions in the general population. Hypertension 42: 685-692.

30. Wagoner LE, Craft LL, Singh B, Suresh DP, Zengel PW, et al. (2000) Polymorphisms of the beta(2)-adrenergic receptor determine exercise capacity in patients with heart failure. Circ Res 86: 834-840.

31. Scott MG, Swan C, Wheatley AP, Hall IP (1999) Identification of novel polymorphisms within the promoter region of the human beta2 adrenergic receptor gene. Br J Pharmacol 126: 841-844

32. Bengtsson K, Orho-Melander M, Melander O, Lindblad U, Ranstam J, et al (2001) Beta(2)-adrenergic receptor gene variation and hypertension in subjects with type 2 diabetes. Hypertension 37: 1303-1308.

33. Tan LJ, Zhu H, He H, Wu KH, Li J, et al. (2014) Replication of 6 obesity genes in a meta-analysis of genome-wide association studies from diverse ancestries. PLoS One 9: e96149.

34. Leineweber K, Büscher R, Bruck H, Brodde OE (2004) Beta-adrenoceptor polymorphisms. Naunyn Schmiedebergs Arch Pharmacol 369: 1-22.

35. Kurokawa N, Young EH, Oka Y, Satoh H, Wareham NJ, et al. (2008) The ADRB3 Trp64Arg variant and BMI: a meta-analysis of 44833 individuals. Int J
Obes (Lond) 32: 1240-1249.

36. Umekawa T, Yoshida T, Sakane N, Kogure A, Kondo M, et al. (1999) Trp64Arg mutation of beta3-adrenoceptor gene deteriorates lipolysis induced by beta3 adrenoceptor agonist in human omental adipocytes. Diabetes 48: 117-120.

37. Liu ZQ, Mo W, Huang Q, Zhou HH (2007) Genetic polymorphisms of human beta-adrenergic receptor genes and their association with obesity. Zhong Nan Da Xue Xue Bao Yi Xue Ban 32: 359-367.

38. Rathz DA, Brown KM, Kramer LA, Liggett SB (2002) Amino acid 49 polymorphisms of the human beta1-adrenergic receptor affect agonistpromoted trafficking. J Cardiovasc Pharmacol 39: 155-160.

39. Mason DA, Moore JD, Green SA, Liggett SB (1999) A gain-of-function polymorphism in a G-protein coupling domain of the human beta1-adrenergic receptor. J Biol Chem 274: 12670-12674.

40. Liu J, Liu ZQ, Tan ZR, Chen XP, Wang LS, et al. (2003) Gly389Arg polymorphism of beta1-adrenergic receptor is associated with the cardiovascular response to metoprolol. Clin Pharmacol Ther 74: 372-379.

41. Rydén M, Hoffstedt J, Eriksson P, Bringman S, Arner P (2001) The Arg 389 Gly beta1-adrenergic receptor gene polymorphism and human fat cell lipolysis. Int J Obes Relat Metab Disord 25: 1599-1603.

42. Dionne IJ, Garant MJ, Nolan AA, Pollin TI, Lewis DG, et al. (2002) Association between obesity and a polymorphism in the beta(1)-adrenoceptor gene (Gly389Arg ADRB1) in Caucasian women. Int J Obes Relat Metab Disord 26 : 633-639.

43. Gjesing AP, Andersen G, Albrechtsen A, Glümer C, Borch-Johnsen K, et al. (2007) Studies of associations between the Arg389Gly polymorphism of the beta1-adrenergic receptor gene (ADRB1) and hypertension and obesity in 7677 Danish white subjects. Diabet Med 24: 392-397.

44. Ellsworth DL, Coady SA, Chen W, Srinivasan SR, Boerwinkle E, et al. (2005) Interactive effects between polymorphisms in the beta-adrenergic receptors and longitudinal changes in obesity. Obes Res 13: 519-526.

45. Vosselman MJ, van der Lans AA, Brans B, Wierts R, van Baak MA, et al. (2012) Systemic $\beta$-adrenergic stimulation of thermogenesis is not accompanied by brown adipose tissue activity in humans. Diabetes 61: 3106-3113.

46. Parysow O, Mollerach AM, Jager V, Racioppi S, San Roman J, et al. (2007) Low-dose oral propranolol could reduce brown adipose tissue F-18 FDG uptake in patients undergoing PET scans. Clin Nucl Med 32: 351-357.

47. Arch JR, Wilson S (1996) Prospects for beta 3-adrenoceptor agonists in the treatment of obesity and diabetes. Int J Obes Relat Metab Disord 20: 191-199.

48. Mantzoros CS, Qu D, Frederich RC, Susulic VS, Lowell BB, et al. (1996) Activation of beta(3) adrenergic receptors suppresses leptin expression and mediates a leptin-independent inhibition of food intake in mice. Diabetes 45 909-914.

49. Weyer C, Tataranni PA, Snitker S, Danforth E Jr, Ravussin E (1998) Increase in insulin action and fat oxidation after treatment with $C L 316,243$, a highly selective beta3-adrenoceptor agonist in humans. Diabetes 47: 1555-1561.

50. Kurylowicz A, Jonas M, Lisik W, Jonas M, Wicik Z, et al. (2015) Obesity is associated with a decrease in expression but not with the hypermethylation of thermogenesis-related genes in adipose tissues. J Transl Med 13: 31

51. Cheng SY, Leonard JL, Davis PJ (2010) Molecular aspects of thyroid hormone actions. Endocr Rev 31: 139-170.

52. Nannipieri M, Cecchetti F, Anselmino M, Camastra S, Niccolini $P$, et al. (2009) Expression of thyrotropin and thyroid hormone receptors in adipose tissue of patients with morbid obesity and/or type 2 diabetes: effects of weight loss. Int $J$ Obes (Lond) 33: 1001-1006.

53. Prats-Puig A, Sitjar C, Ribot R, Calvo M, Clausell-Pomés N, et al. (2012) Relative hypoadiponectinemia, insulin resistance, and increased visceral fat in euthyroid prepubertal girls with low-normal serum free thyroxine. Obesity (Silver Spring) 20: 1455-1461.

54. Alevizaki M, Saltiki K, Voidonikola P, Mantzou E, Papamichael C, et al. (2009) Free thyroxine is an independent predictor of subcutaneous fat in euthyroid individuals. Eur J Endocrinol 161: 459-465.

55. Soriguer F, Valdes S, Morcillo S, Esteva I, Almaraz MC, et al. (2011) Thyroid hormone levels predict the change in body weight: a prospective study. Eur $\mathrm{J}$ Clin Invest 41: 1202-1209.

56. Feldt-Rasmussen U (2007) Thyroid and leptin. Thyroid 17: 413-419. 
Citation: Kurylowicz A (2015) Stimulation of Thermogenesis via Beta-Adrenergic and Thyroid Hormone Receptors Agonists in Obesity Treatment Possible Reasons for Therapy Resistance. J Pharmacogenomics Pharmacoproteomics 6: 145. doi:10.4172/2153-0645.1000145

57. Pelletier P, Gauthier K, Sideleva O, Samarut J, Silva JE (2008) Mice lacking the thyroid hormone receptor-alpha gene spend more energy in thermogenesis, burn more fat, and are less sensitive to high-fat diet-induced obesity. Endocrinology 149: 6471-6486.

58. Dumitrescu AM, Refetoff S (2013) The syndromes of reduced sensitivity to thyroid hormone. Biochim Biophys Acta 1830: 3987-4003.

59. Kaneshige M, Kaneshige K, Zhu X, Dace A, Garrett L, et al. (2000) Mice with a targeted mutation in the thyroid hormone beta receptor gene exhibit impaired growth and resistance to thyroid hormone. Proc Natl Acad Sci U S A 97: 13209 13214

60. Mamanasiri S, Yesil S, Dumitrescu AM, Liao XH, Demir T, et al. (2006) Mosaicism of a thyroid hormone receptor-beta gene mutation in resistance to thyroid hormone. J Clin Endocrinol Metab 91: 3471-3477.

61. Mitchell CS, Savage DB, Dufour S, Schoenmakers N, Murgatroyd P, et al. (2010) Resistance to thyroid hormone is associated with raised energy expenditure, muscle mitochondrial uncoupling, and hyperphagia. J Clin Invest 120: 1345-1354.

62. Schoenmakers N, Moran C, Peeters RP, Visser T, Gurnell M, et al. (2013) Resistance to thyroid hormone mediated by defective thyroid hormone receptor alpha. Biochim Biophys Acta 1830: 4004-4008.

63. Fernández-Real JM, Corella D, Goumidi L, Mercader JM, Valdés S, et al. (2013) Thyroid hormone receptor alpha gene variants increase the risk of developing obesity and show gene-diet interactions. Int J Obes (Lond) 37: 1499-1505.

64. Sørensen HG, van der Deure WM, Hansen PS, Peeters RP, Breteler MM, et al. (2008) Identification and consequences of polymorphisms in the thyroid hormone receptor alpha and beta genes. Thyroid 18: 1087-1094.

65. Oh SS, Kaplan ML (1994) Early treatment of obese (ob/ob) mice with triiodothyronine increases oxygen consumption and temperature and decreases body fat content. Proc Soc Exp Biol Med 207: 260-267.
66. Kaptein EM, Beale E, Chan LS (2009) Thyroid hormone therapy for obesity and nonthyroidal illnesses: a systematic review. J Clin Endocrinol Metab 94: 3663-3675.

67. Villicev CM, Freitas FR, Aoki MS, Taffarel C, Scanlan TS, et al. (2007) Thyroid hormone receptor beta-specific agonist GC-1 increases energy expenditure and prevents fat-mass accumulation in rats. J Endocrinol 193: 21-29.

68. Amorim BS, Ueta CB, Freitas BC, Nassif RJ, Gouveia CH, et al. (2009) A TRbeta-selective agonist confers resistance to diet-induced obesity. J Endocrinol 203: 291-299.

69. Castillo M, Freitas BC, Rosene ML, Drigo RA, Grozovsky R, et al. (2010) Impaired metabolic effects of a thyroid hormone receptor beta-selective agonist in a mouse model of diet-induced obesity. Thyroid 20: 545-553.

70. Bryzgalova G, Effendic S, Khan A, Rehnmark S, Barbounis P, et al. (2008) Anti-obesity, anti-diabetic, and lipid lowering effects of the thyroid receptor beta subtype selective agonist KB-141. J Steroid Biochem Mol Biol 111: 262-267.

71. Baxter JD, Webb P (2009) Thyroid hormone mimetics: potential applications in atherosclerosis, obesity and type 2 diabetes. Nat Rev Drug Discov 8: 308-320.

72. Ribeiro MO, Carvalho SD, Schultz JJ, Chiellini G, Scanlan TS, et al. (2001) Thyroid hormone--sympathetic interaction and adaptive thermogenesis are thyroid hormone receptor isoform-specific. J Clin Invest 108: 97-105.

73. Decherf S, Seugnet I, Kouidhi S, Lopez-Juarez A, Clerget-Froidevaux MS, et al. (2010) Thyroid hormone exerts negative feedback on hypothalamic type 4 melanocortin receptor expression. Proc Natl Acad Sci U S A 107: 4471-4476.

74. Grijota-Martínez C, Samarut E, Scanlan TS, Morte B, Bernal J (2011) In vivo activity of the thyroid hormone receptor beta- and $\alpha$-selective agonists GC-24 and $\mathrm{CO} 23$ on rat liver, heart, and brain. Endocrinology 152: 1136-11 